\title{
Visual communication in lean organizations
}

\author{
Maria Virginia Iuga ${ }^{1+2, *}$ \\ ${ }^{1}$ Marquardt Schaltsysteme S.C.S., 2, München st., 550018 Sibiu, Romania \\ ${ }^{2}$ Lucian Blaga University of Sibiu, Faculty of Engineering, 10 Victoriei Bvd., 550024 Sibiu, Romania
}

\begin{abstract}
Many researchers have studied the role and importance of communication and communication types for organizations and their work force. The topic of organizational communication is a constantly changing one. The thing that remains stable throughout this very wide topic is its purpose: communication is vital for the effectiveness and success of organizations of all sizes, types and cultures. In terms of type, one could split up topic by type as followed: verbal, visual and written. This research paper focuses on the visual component at shop floor within automotive organizations. It aims at giving the reader a structured overview on the most appropriate but also lean visual communication practices. In order to establish these methods at shop floor, a survey was conducted among nine big automotive companies in Romania. It was then followed up by a second survey dedicated to check the effectiveness of implementation of these methods in a big automotive organization. The paper presents the analyses, results and the conclusions of this surveys.
\end{abstract}

\section{Introduction}

In the very competitive automotive industry, but not only there, the lean concept and philosophy gain credibility more and more, due to the really improvements of organizations' results. In the actual global market economy, the focus on efficiency increased dramatically and lean manufacturing implementation helped organizations to get the best results through very simple approaches, primarily orientated to avoiding wastes. Organizational communication is one of the most important components of lean philosophy and the savings potentials due to a lean communication must be taken into consideration.

Current, at the shop floor there are three arts of communication which coexist: visual, verbal and written (typed information through email). In order to remove the waste (Jap: muda) created by misunderstandings, written communication must be as visual as possible. In lean manufacturing, it is essential to use the appropriate visual languages in general and visualization in particular to maximize human visual perceptual power for rapid and effective communication in management [1]. According to current trends, the visualization in shop floor management can be defined as the slogan "five minutes shop floor instead of fifty management minute of presentation" [2]. An advanced visual management means "the ability to understand the status of a production area in five minutes or less, by simple

\footnotetext{
* Corresponding author: virginiaiuga@gmail.com
} 
observation, without using a computer and without talking to anyone [3]. The idea of lean communication refers to a visually transparent management system, leading to the identification of wastes in Gemba and therefore to the necessary action to eliminate these.

The research targeted an analysis of the actual stage of shop floor visual communication in order to define the most appropriate and efficient methods and tools. The method used within this research paper consisted of two questionnaires. The first step used a survey, conducted in Romania among eight automotive companies. A ranking of most appropriate visualization methods was obtained. The second step performed an analysis of changes after the implementation of shop floor management in a big automotive company, having over 2500 employees in area Sibiu, Romania. This analysis was performed using the second survey and it targeted on one hand, the perception of employees regarding the effectiveness of new implemented lean visualizations methods and, on the other hand, the improvements regarding time management due to improved shop floor communication.

\section{Survey design and procedures}

In order to project the ideal model of visual management at shop floor, a survey named "Effectiveness and Visualization at Shop Floor" was designed (2013). The questioned persons were asked to assess the efficiency of nine different visualization methods at shop floor. The question was used in combination with a five-point scale (1-"very efficient" to 5 - "inefficient"). Depending on the area of application, the visualization methods were clustered in three categories: central visualizations - representative for the entire production area, zonal ones - representative for groups of machines or production lines and local visualization - representative for one line/machine. The proposal of other methods from the respondents remains open.

The questionnaire was handed out using a mailing action within automotive companies from Romania but was also posted within various specialty groups regarding lean manufacturing using the professional social media platform "LinkedIn". The survey was distributed using two different hyperlinks which served the purpose of segmenting two different types of respondents. The hyperlink to the survey was then distributed via online and social media channels. One link was distributed via the social media channel LinkedIn. The second hyperlink was distributed via an emailing action throughout production companies within nine companies from the automotive sector. The completion of the surveys was completely anonymous. For the completion of the questionnaire, no incentive or reward was offered to the participants. The time frame for which the questionnaire was available for completion was three weeks in March 2013.

Within the data analysis, the descriptive statistics along with the frequency distributions were analyzed. The measures of central tendency have also been taken into consideration. While the mode indicated the score that appeared most frequently in the data set, the median helped indicate the center of a distribution and locate the middle score when scores are ranked in order of magnitude. The mean is the measure of central tendency that shows the average score of the data set [4]. All procedures reported here utilized SPSS 20.0.

\section{Data collection and sample profile}

\subsection{Data collection}

The situation of collected responses was centralized Table 1. Within the data collection process, 88 surveys were filled out without any missing values from totally of 157 participants. After a thorough examination of the responses, one of these surveys was 
filtered out even if it did not contain any missing values. The reason for the exclusion of this survey was the indication of a response pattern. Therefore, 87 surveys went into the data analysis process. Table 1 illustrates the situation of collected responses:

Table 1. Collected responses

\begin{tabular}{ccc}
\hline & Total responses & Valid responses \\
\hline LinkedIn & 37 & 24 \\
Romanian automotive organizations & 120 & 63 \\
\hline
\end{tabular}

\subsection{Sample profile}

In order to identify the provenience of the answers respondents were asked to indicate:

- Which area of work they activate in.

- What company type they work at.

- What hierarchical level they are working on.

- Size of the company the respondents currently work at.

- Whether they are leading shop floor employees or not.

- Whether they are directly leading personnel or not.

The answers are presented in figures 1 to 4 . The data sets proved that the selected sample was very representative for a general population of employees which work in industry $(96 \%)$, especially in automotive industries $(80.5 \%)$ and in big companies with more than 1000 employees (77\%). Furthermore, the sample represents in its majority persons working within production departments, proportionally for each hierarchical level.

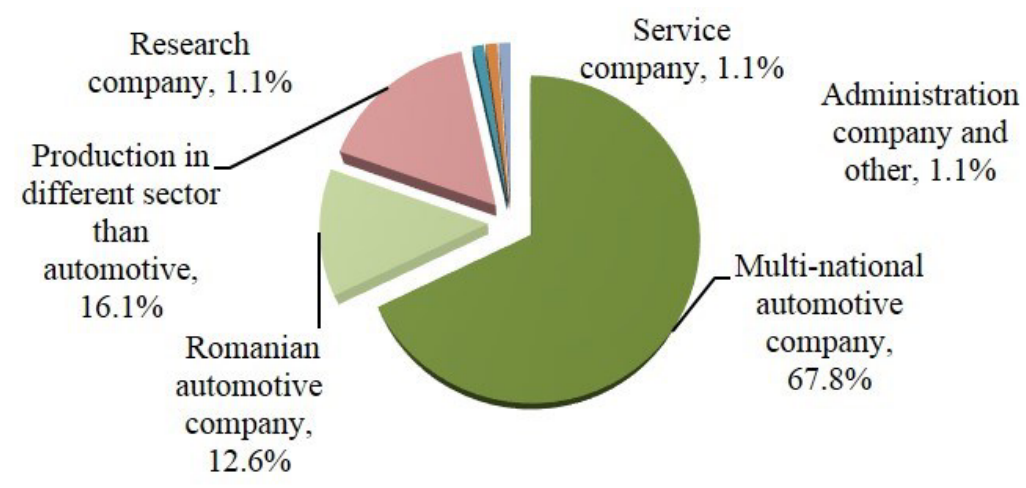

Fig. 1. Sample company type

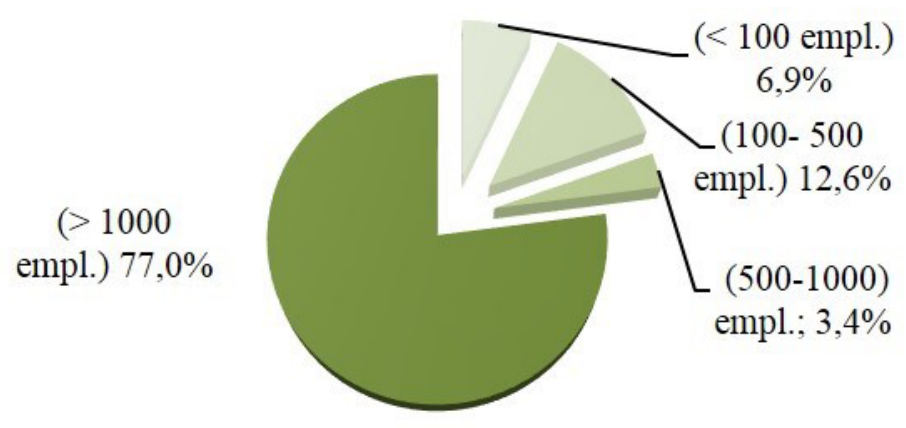

Fig. 2. Sample company size 


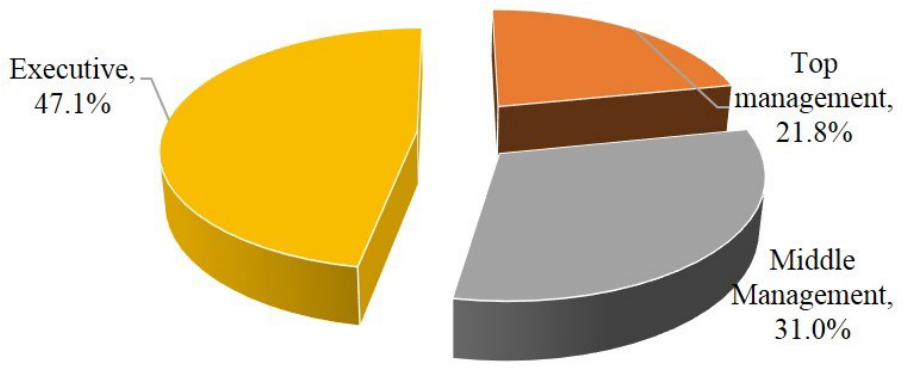

Fig. 3. Sample hierarchy

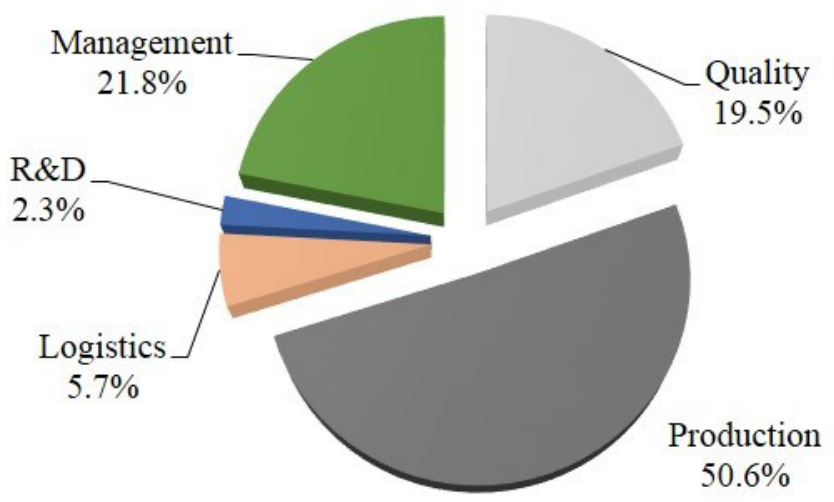

Fig. 4. Respondents sample area of work

\section{Survey results}

In order to assess the shop floor visualization methods to the previous mentioned questionnaire the participants were asked to evaluate the efficiency of nine most usual forms of visualization at shop floor. This question was used in combination with a fivepoint scale (1-"very efficient" to 5 -"inefficient"). The respondents were asked to indicate how efficient the nine shop floor visualization methods are in their opinions and to propose other methods which were not asked. Table 2 gives a structured overview of the nine chosen visualization methods. The respondents had to evaluate five shop floor central and zonal visualization methods and four visualization methods used only local, per machinery/production line.

Table 2. Communication through visualization at shop floor

\begin{tabular}{|l|l|l|}
\hline $\begin{array}{l}\text { Item } \\
\text { No. }\end{array}$ & \multicolumn{1}{|c|}{ Visualization method } & Abbreviation \\
\hline 1 & $\begin{array}{l}\text { Central/ zonal: panel (electronic) for a production area showing the } \\
\text { operating status of all machines in the area (ANDON CENTRAL) }\end{array}$ & CZELPA \\
\hline 2 & $\begin{array}{l}\text { Central/ zonal: displays for general information (statistics, events, days } \\
\text { off, etc.) with data derived from a central computer }\end{array}$ & CZDIS \\
\hline 3 & $\begin{array}{l}\text { Central/ zonal: information panels on production areas containing } \\
\text { statistical data listed on paper and updated at least once a month }\end{array}$ & CZINPA \\
\hline 4 & $\begin{array}{l}\text { Zonal: Paper holders (flip Figures) with interactive data updated by } \\
\text { employees }\end{array}$ & ZPAHO \\
\hline 5 & Zonal: White board with interactive data updated daily by employees & ZWHBO \\
\hline 6 & Per production line: electronic screen at every line (machinery) based & PPLELS \\
\hline
\end{tabular}




\begin{tabular}{|l|l|l|}
\hline $\begin{array}{l}\text { Item } \\
\text { No. }\end{array}$ & \multicolumn{1}{|c|}{ Visualization method } & Abbreviation \\
\hline & $\begin{array}{l}\text { on electronic data updates of production data (produced quantities, } \\
\text { defects, etc.) and real time visualization }\end{array}$ & \\
\hline 7 & $\begin{array}{l}\text { Per production line: board at the end of the line (machinery) based on } \\
\text { interactive updates of the shop floor employees }\end{array}$ & PPLBILB \\
\hline 8 & $\begin{array}{l}\text { Per production line: stoplight indicator, operated automatically, } \\
\text { indicating the operating status of the production line (ANDON) }\end{array}$ & PPLSTA \\
\hline 9 & $\begin{array}{l}\text { Per production line: stoplight indicator, operated manually, indicating } \\
\text { the operating status of the production line (ANDON) }\end{array}$ & PPLSTM \\
\hline
\end{tabular}

The order in which the respondents assessed these visualization methods to be efficient was randomly selected as follows: PPLELS, PPLSTA, ZWHBO, CZELPA, PPLBILB, PPLSTM, ZPAHO, CZDIS and CZINPA.

The visualization method regarding an electronic screen at every line based on electronic data updated and real time visualization (PPLELS) was assessed as being very efficient by $66.7 \%$ of the sample. Only $2.3 \%$ of the sample (two respondents) considered this visualization method to be inefficient $(\mathrm{M}=1.60, \mathrm{SD}=1.017)$.

The stoplight indicator operated automatically (ANDON) (PPLSTA) was considered to be the next most efficient visualization method, $59.8 \%$ of the sample considered this visualization method to be very efficient. Only three respondents indicated that in their opinion this visualization method is very inefficient $(\mathrm{M}=1.71, \mathrm{SD}=1.056)$. White board with interactive data updated daily by employees (ZWHBO) was assessed as being the third most efficient visualization method with a valid percent of $55.2 \%$ indicating that the method is very efficient $(\mathrm{M}=1.76, \mathrm{SD}=1.078)$.

The fourth most efficient visualization method was CZELPA, the panel (electronic) for a production area showing the operating status of all machines in the area (ANDON CENTRAL), $56.3 \%$ of the sample assessed this method as being very efficient and only two respondents as being inefficient $(\mathrm{M}=1.77, \mathrm{SD}=1.064)$. Table 3 and Figure 5 offer a preview of all frequency distributions for the nine visualization methods.

Table 3. Visualization methods ranking

\begin{tabular}{|c|c|c|c|c|c|c|c|c|c|}
\hline & CZELPA & CZDIS & CZINPA & ZPAHO & ZWHBO & PPLELS & PPLBILB & PPLSTA \\
\hline \multirow{2}{*}{$\mathrm{N}$} & Valid & 87 & 87 & 87 & 87 & 87 & 87 & 87 & 87 \\
\hline & Missing & 0 & 0 & 0 & 0 & 0 & 0 & 0 & 0 \\
\hline \multicolumn{2}{|c|}{ Mean (Ti) } & 1.77 & 2.66 & 2.82 & 2.38 & 1.76 & 1.60 & 1.80 & 1.71 \\
\hline \multicolumn{2}{|c|}{$\begin{array}{l}\text { Std. Error } \\
\text { of Mean }\end{array}$} & .114 & .163 & .161 & .140 & .116 & .109 & .118 & .113 \\
\hline \multicolumn{2}{|c|}{ Median } & 1.00 & 2.00 & 3.00 & 2.00 & 1.00 & 1.00 & 1.00 & 1.00 \\
\hline \multicolumn{2}{|c|}{ Mode } & 1 & 1 & 1 & 1 & 1 & 1 & 1 & 1 \\
\hline \multicolumn{2}{|c|}{$\begin{array}{l}\text { Std. } \\
\text { Deviation }\end{array}$} & 1.064 & 1.516 & 1.498 & 1.305 & 1.078 & 1.017 & 1.098 & 1.056 \\
\hline \multicolumn{2}{|c|}{ Variance } & 1.133 & 2.298 & 2.245 & 1.703 & 1.162 & 1.034 & 1.206 & 1.114 \\
\hline
\end{tabular}




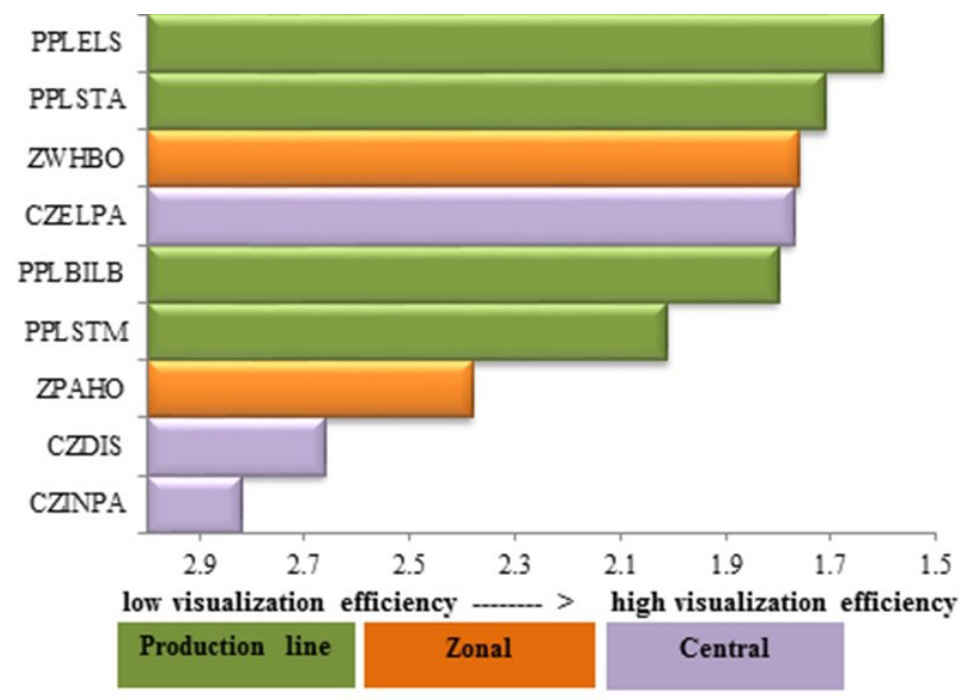

Fig. 5. Range of visualization methods

\section{Case study results}

Considering the efficiency of the visualization methods, the following arts of visualization are the most efficient: for the production line: PPLELS, PPLSTA, PPLBILB, and PPLSTM and for larger production areas ZWHBO and CZELPA. Illustrations of these visualizations are presented below in Figure 6.

According to the results of survey regarding the visualization methods the ones which should be avoided, are CZDIS, CZINPA, and ZPAHO.

Effectiveness analyse for implementation of these visualization methods was performed in a big automotive company (over 2500 employees) in Romania using a questionnaire. The analyse was performed about one year after implementation of shop floor management which included the recommended visualisation methods. The following results have been recorded:

- Regarding employees perception, the respondents were asked to indicate whether the implemented visualization methods have a higher, lower or the same utility as other visualization methods used before introducing the lean shop floor management standards. Most of the respondents $(68.2 \%)$ indicated that the new visualization methods have a much higher utility than older visualization methods used in the company. $22.4 \%$ indicated that there is no difference regarding utility and only less than $10 \%(9.4 \%)$ indicated that the new visualization methods have a lower utility than older ones.

- Regarding time management, due to implementation of lean communication at shop floor, improvements were found at the top management level, where a saving of 5.5-7.6 hours/ month was recorded, followed by savings consisting on an average of three hours a day for middle management [5]. 


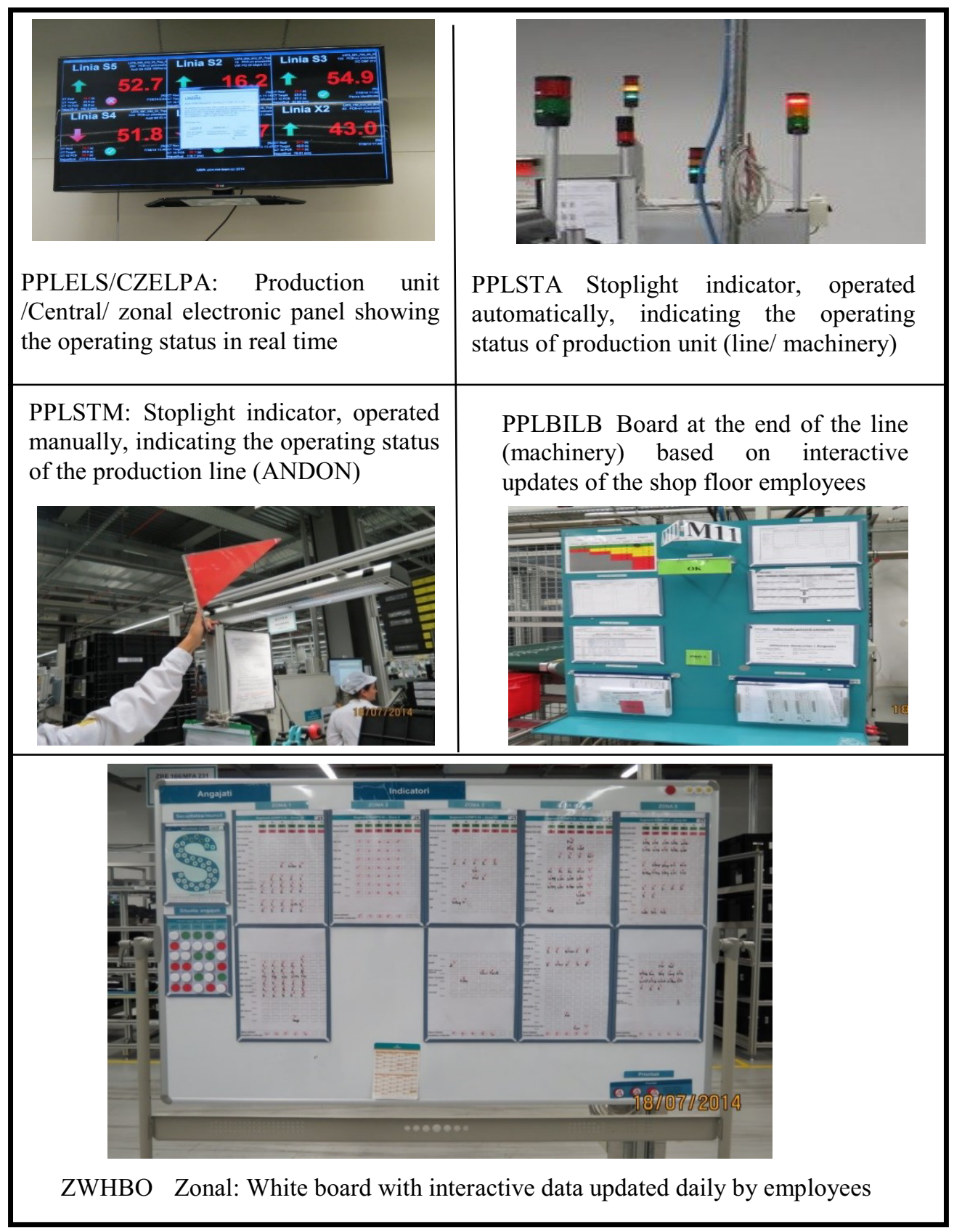

Fig. 6. Types of visual communication at shop floor

\section{Conclusions}

The conclusions of the research can help manufacturing organizations select the most efficient art of visualization at shop floor according to the lean manufacturing philosophy, in order to avoid the waste created through inappropriate visual communication. Adopting 
one or several combined recommended solutions can lead to a better shop floor information flow with a minimum of resources consumption. The visualization of relevant information directly at shop floor should assure a high level of transparency for everybody.

The best ranked lean solutions for production units (machinery/line) are to apply real time visualization assured through electric boards at each production unit and /or stoplight indicators, operated automatically. At the same time for zonal/central visual management white boards with interactive data updated daily by employees are recommended to be standardized at shop floor. These boards should contain KPIs, which can be tracked with standardized work sheets in handwritten visualizations.

The implementation of this kind of interactive visualization lead to an intensely deal with the processes and problems from employees and managers. The information boards on shop floor serve on one hand as a communication tool throughout the employees and on the other hand to spread direct shop floor information to all management levels.

The implementation of most appropriate visualization methods has led to measurable improvements and savings.

Limitations: beside the LinkedIn area of research, the questionnaire regarding visual management was directly conducted in only nine Romanian organizations. Further research in this area should concentrate on iterating these analyses in other automotive organizations in Eastern Europe where this industry is younger and growing. The aim of this entire action is to design lean bases visualization in shop floor and transparent visual management system, so that the administration can recognize the need to act in a timely manner.

\section{References}

1. K. Zhang, J. Visual Languages \& Computing, 23 (6), 340 (2012)

2. http://www.staufen.ag/fileadmin/Brochures/brochure-staufen-shopfloor-management-en.pdf, Accesed 18.03.2017

3. M. Imai, Gemba Kaizen: A Commonsense, Low-Cost Approach to Management (McGraw Hill Professional, 1997)

4. A. Field, Discovering statistics using IBM SPSS statistics (Sage 2013)

5. M.V. Iuga, C.V. Kifor, I. Bondrea, Proceedings of 18th QMOD-ICQSS Conference, Seoul, 한국품질경영학회 추계학술발표논문집, 458 (2015) 